\title{
Effects of field warming on a High Arctic soil bacterial community: a metagenomic analysis
}

\author{
P. P. J. Lim ${ }^{1}$, K. K. Newsham ${ }^{2}$, P. Convey ${ }^{1,2}$, H. M. Gan ${ }^{3,4}$, W. C. Yew ${ }^{1}$ and \\ G. Y. A. $\operatorname{Tan}^{1, *}$ \\ ${ }^{1}$ National Antarctic Research Centre and Institute of Biological Sciences, University of Malaya, 50603 Kuala Lumpur, Malaysia \\ ${ }^{2}$ British Antarctic Survey, NERC, High Cross, Madingley Road, Cambridge CB3 OET, United Kingdom \\ ${ }^{3}$ School of Science and Genomics Facility, Monash University Malaysia, Jalan Lagoon Selatan, Bandar Sunway, 47500 Subang Jaya, Malaysia \\ ${ }^{4}$ Centre for Integrative Ecology, School of Life and Environmental Sciences, Deakin University, Geelong 3220, Australia
}

Soil microbial communities in the Arctic, one of the most rapidly warming regions on Earth, play an important role in a range of ecological processes. This report describes initial studies of natural soil bacterial diversity at a High Arctic site on Svalbard, as part of a long-term field environmental manipulation study. The impact of increased soil temperature and water availability on soil microbial communities was investigated. The manipulation experiment, using open-top chambers, was installed in late summer 2014, and the soils were sampled soon after snow melt in July 2015. High throughput sequencing of 16S rRNA genes showed relatively uniform diversity across the study area and revealed no significant initial effect of treatments on bacterial communities over the first 10-month autumn-winter-spring manipulation period.

Keywords: Arctic soil bacterial diversity, high throughput sequencing, open top chambers, Svalbard.

\section{Introduction}

GLOBAL climate change is predicted to have a greater impact at high latitudes, particularly in the Arctic, which is already warming and is expected to continue warming more quickly than lower latitude regions due to a phenomenon known as polar amplification ${ }^{1,2}$. Climate models predict warmer Arctic winters, which could both increase and decrease local snow cover and change the frequencies of freeze-thaw cycles ${ }^{3}$. Together, these changes may lead to both an increase and decrease in water availability to microbiota, owing to the thawing of ice and greater drainage respectively ${ }^{4}$. Soil microorganisms are fundamental to major global biogeochemical cycles ${ }^{5}$, particularly in polar regions ${ }^{6}$. The objective of the present study was to analyse, using a high throughput sequencing approach, the initial effects of open-top chamber (OTC) warming and water input on Arctic soil bacteria in a representative tundra habitat near Ny-Ålesund, Svalbard.

\footnotetext{
*For correspondence. (e-mail: gyatan@um.edu.my)
}

Data presented here were obtained after a $\sim 10$-month autumn-winter-spring period following OTC deployment.

\section{Experimental design}

The experiment was established on 11 and 12 September 2014 at Kvadehuken on the Brøggerhalvøya Peninsula, Svalbard $\left(78^{\circ} 58.002^{\prime} \mathrm{N}, 11^{\circ} 28.446^{\prime} \mathrm{E}\right)$. Forty-eight plots in three blocks were established in an extensive area of periglacial patterned ground (Figure 1). Warming by OTCs (ITEX chambers ${ }^{7}$ ) and water amendment ( $1 \mathrm{~L}$ of deionized water) were applied in factorial combination to frost boils (Table 1). Soil samples (c. $1 \mathrm{~g}$ ) were collected from each plot on 1 July 2015 and brought to the UK Arctic Research Station at Ny-Ålesund within $3 \mathrm{~h}$ to be frozen at $-20^{\circ} \mathrm{C}$. The frozen soils were subsequently transported to the University of Malaya, Kuala Lumpur, where they were stored at $-20^{\circ} \mathrm{C}$ until further use.

\section{High throughput sequencing and statistical analysis}

Total genomic DNA was extracted from each soil sample using the MoBioPowerSoil DNA extraction kit (MOBIO

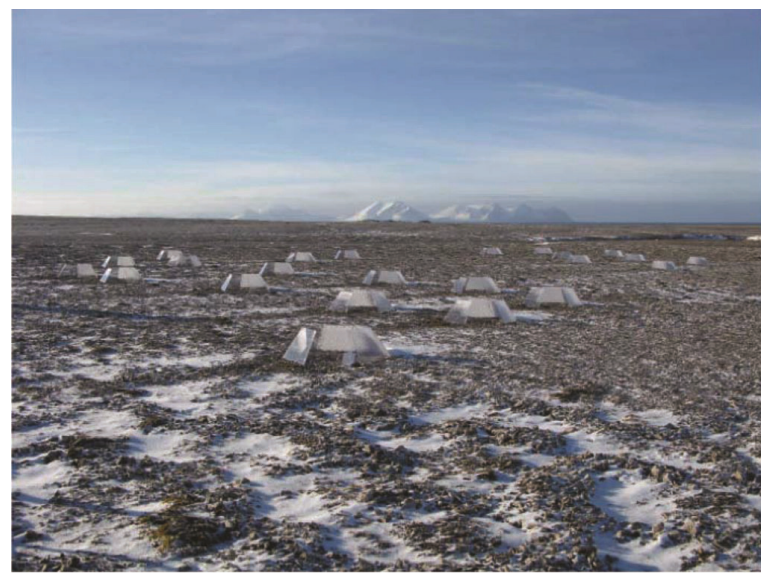

Figure 1. The experimental site at Kvadehuken on the Brøggerhalvøya Peninsula. 
Table 1. Summary of the treatments applied in the simulated warming experiment

\begin{tabular}{|c|c|c|c|c|c|c|c|c|c|c|c|}
\hline 1 & 1 & 0 & 0 & 17 & 2 & 0 & 0 & 33 & 3 & 0 & 0 \\
\hline 3 & 1 & 0 & 1 & 19 & 2 & 0 & 1 & 35 & 3 & 0 & 1 \\
\hline 4 & 1 & 1 & 1 & 20 & 2 & 1 & 1 & 36 & 3 & 1 & 1 \\
\hline 5 & 1 & 0 & 0 & 21 & 2 & 0 & 0 & 37 & 3 & 0 & 0 \\
\hline 8 & 1 & 1 & 1 & 24 & 2 & 1 & 1 & 40 & 3 & 1 & 1 \\
\hline 9 & 1 & 0 & 0 & 25 & 2 & 0 & 0 & 41 & 3 & 0 & 0 \\
\hline 10 & 1 & 1 & 0 & 26 & 2 & 1 & 0 & 42 & 3 & 1 & 0 \\
\hline 11 & 1 & 0 & 1 & 27 & 2 & 0 & 1 & 43 & 3 & 0 & 1 \\
\hline 12 & 1 & 1 & 1 & 28 & 2 & 1 & 1 & 44 & 3 & 1 & 1 \\
\hline 16 & 1 & 1 & 1 & 32 & 2 & 1 & 1 & 48 & 3 & 1 & 1 \\
\hline
\end{tabular}
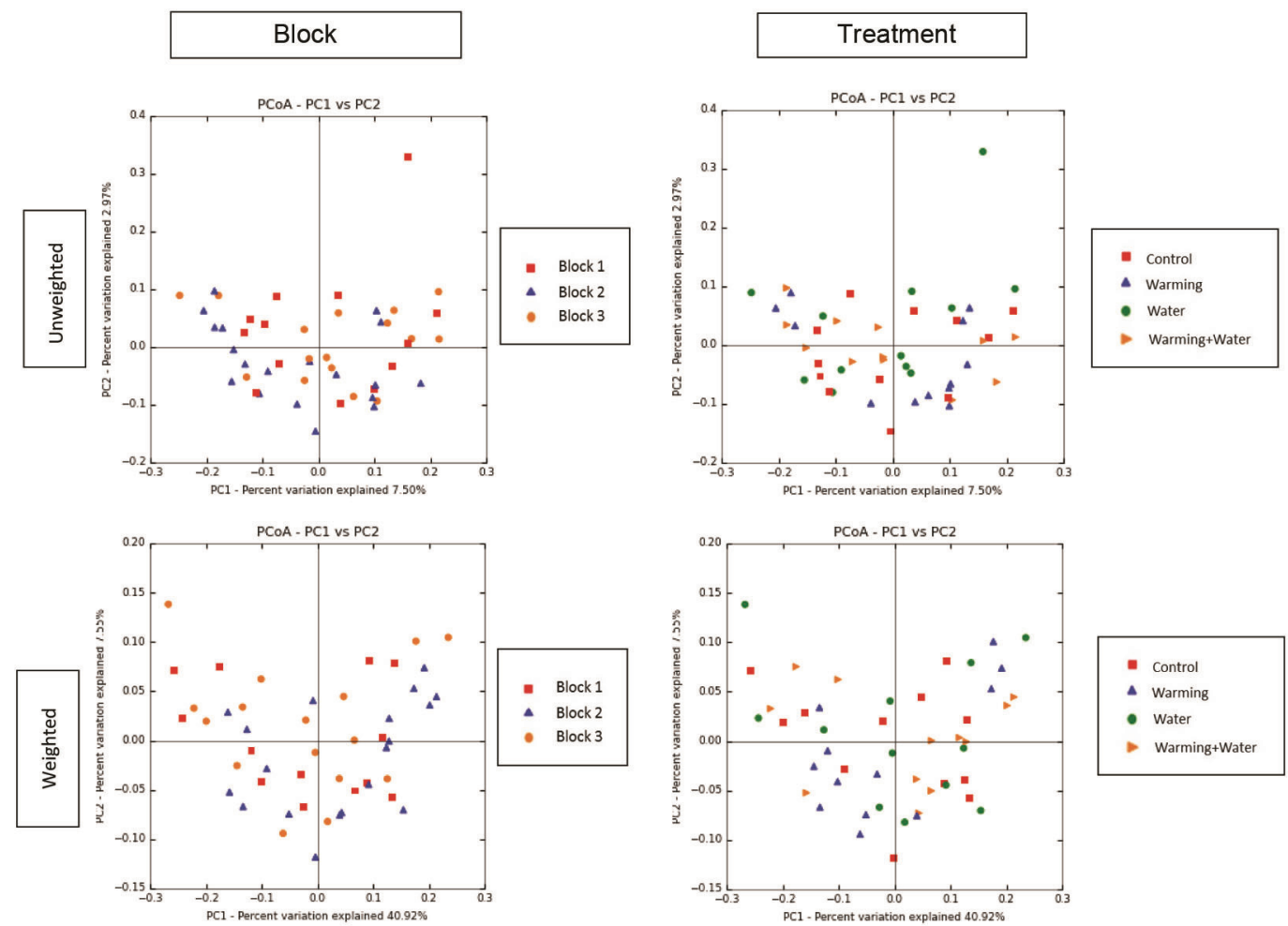

Figure 2. Results of principal coordinate analysis of bacterial communities based on weighted and unweighted UniFrac distance metrics.

Laboratories, CA, USA) according to the manufacturer's instructions. The V3 and V4 hypervariable regions of bacterial $16 \mathrm{~S}$ rRNA genes were amplified by $\mathrm{PCR}^{8}$. Each reaction mixture $(25 \mu \mathrm{l})$ contained $12.5 \mu \mathrm{l}$ of $2 \mathrm{X}$ KAPA HiFi HotStart ReadyMix (Kapa Biosystem, MA, USA), $10 \mu \mathrm{M}$ of each primer, $12 \mathrm{ng}$ of genomic DNA and $10.5 \mu \mathrm{l}$ of ultrapure water with conditions set according to the manufacturer's instructions. Generation of a sequence library was conducted using the MiSeq System
(Illumina Inc., CA, USA) at Monash University, Malaysia Genomics Facility, following the $2 \times 250$-bp pairedend protocol.

The generated demultiplexed sequences were filtered according to base quality $(q=20)$ using CLC Genomic Workbench 8.5. Assembled sequences were processed with QIIME 1.8.0 (ref. 9) with Greengenes ${ }^{10}$ as a resource for taxonomic (OTU) assignment. They were then normalized via random sub-sampling at 1642 reads per 


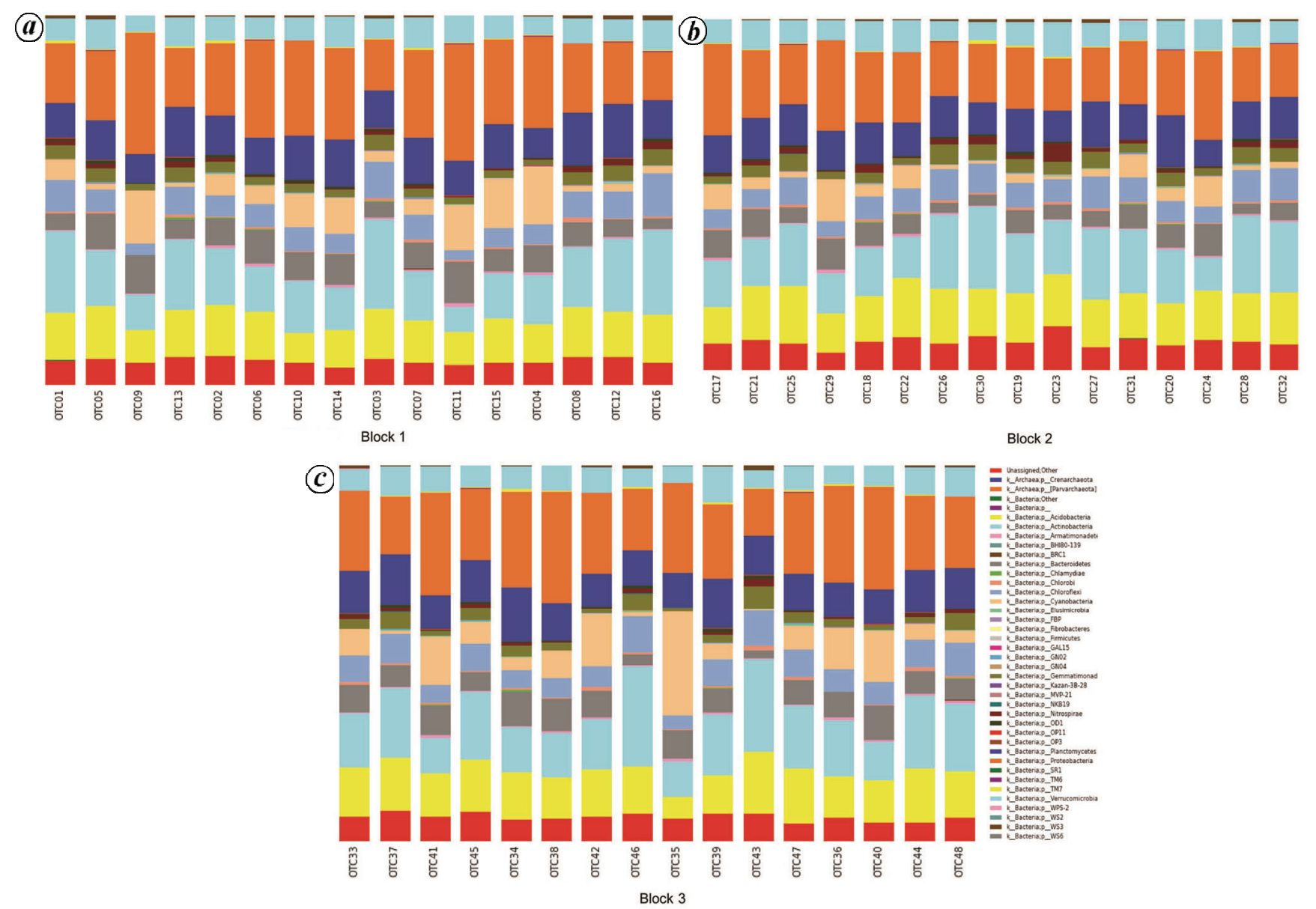

Figure 3. Relative abundances of bacterial taxa at the phylum level in (a) block 1, (b) block 2 and (c) block 3 . Further taxonomic details of each phylum shown here are given in Supplementary Tables 1-3.

sample for alpha-diversity and beta-diversity calculations. UniFrac distances, both weighted and unweighted, were computed among all the samples to generate principal coordinate analysis (PCoA) plots. To test for significant differences in the mean PC1 scores of both the weighted and unweighted UniFrac distances between blocks and treatments, one-way ANOVA was conducted with a post hoc comparison using Tukey's Honestly Significant Difference (HSD) test (IBM SPSS Windows version 19.0, NY, USA).

\section{Results and discussion}

Bacterial community composition at the OTU level was unaffected by either the OTC warming treatment or water amendment at an early stage of the field manipulation experiment (Figure 2). The community composition was also spatially uniform across the three experimental blocks in the field (Figure 3). ANOVA with Tukey's HSD showed that no significant differences were present in the weighted or unweighted UniFrac PC1 scores between the different treatments in each of the three blocks individually, or between the three blocks (data not shown). No differences were apparent in the patterns of predominant bacterial phyla in soil from the different treatments and experimental blocks. The most abundant bacterial phyla were the Proteobacteria, Actinobacteria, Acidobacteria, Planctomycetes, Cyanobacteria, Chloroflexi, Bacteroidetes, Cyanobacteria and Verrucomicrobia (Figure 3). These represent previous Arctic soil records: for instance Acidobacteria, Bacteroidetes and Proteobacteria were all found to be frequent in permafrost of north-east Greenland $^{11}$.

Our results demonstrate that 10 months of warming with OTCs did not influence the bacterial community composition of the studied soil, or the relative abundance of the predominant phyla. An absence of treatment effects, during a period in which the mean soil temperatures in control and chambered plots were $-1.81^{\circ} \mathrm{C}$ and $-1.19^{\circ} \mathrm{C}$ respectively, was not surprising as treatment effects of OTCs are usually restricted to the summer months ${ }^{12,13}$.

Other studies also show that Arctic soil microbial communities respond very slowly to warming treatments. Experiments using OTCs to warm High Arctic soils have shown significant changes in community structure and 
genotype richness of nitrous oxide-reducing and atmospheric nitrogen-fixing bacterial genes in soil, but only after 13 years. However, the most pronounced effects were recorded in wet meadows, suggesting the importance of water in determining microbial responses to warming treatments ${ }^{14}$. Such water-dependent warming effects have also been observed in fungal community responses to warming treatments of Arctic soils ${ }^{15}$.

In conclusion, this initial study found no immediate effects of warming and water amendment on soil bacterial communities of Svalbard. Bacterial taxa variation between blocks and the number of OTUs present in soil was found to be negligible, indicating that this is a suitable experiment in which to detect changes in bacterial community composition in response to environmental manipulations in future.

The metagenome sequence data from this study have been deposited in NCBI under the Sequence Read Archive (SRA) database with accession number SRP105234 and BioProject number PRJNA356212.

1. Symon, C., Arris, L. and Heal, B. (eds), Arctic Climate Impact Assessment, Cambridge University Press, Cambridge, UK, 2005.

2. Intergovernmental Panel on Climate Change, Climate Change 2014 - Impacts, Adaptation and Vulnerability: Regional Aspects, Cambridge University Press, 2014, pp. 3-5.

3. Cooper, E. J., Warmer shorter winters disrupt arctic terrestrial ecosystems. Annu. Rev. Ecol. Evol. Syst., 2014, 45, 271-295.

4. AMAP. Snow, Water, Ice and Permafrost in the Arctic (SWIPA): Climate Change and the Cryosphere. Arctic Monitoring and Assessment Programme (AMAP), Oslo, 2011.

5. Falkowski, P. G., Fenchel, T. and Delong, E. F., The microbial engines that drive Earth's biogeochemical cycles. Science, 2008, 320, 1034-1039.

6. Vincent, W. F., Rae, R., Laurion, I., Howard-Williams, C. and Priscu, J. C., Transparency of Antarctic ice-covered lakes to solar UV radiation. Limnol. Oceanogr., 1998, 43, 618-624.

7. Henry, G. H. R. and Molau, U., Tundra plants and climate change: the International Tundra Experiment (ITEX). Glob. Chang. Biol., 1997, 3, 1-9.
8. Klindworth, A., Pruesse, E., Schweer, T. and Peplies, J., Quast, C., Horn, M. and Glöckner, F. O., Evaluation of general $16 \mathrm{~S}$ ribosomal RNA gene PCR primers for classical and next generation sequencing based diversity studies. Nucleic Acids Res., 2013, 41, e1.

9. Caporaso, J. G. et al., QIIME allows analysis of high-throughput community sequencing data. Nat. Methods, 2010, 7, 335-336.

10. McDonald, D. et al., An improved greengenes taxonomy with explicit ranks for ecological and evolutionary analyses of bacteria and archaea. ISME J., 2012, 6, 610-618.

11. Ganzert, L., Bajerski, F. and Wagner, D., Bacterial community composition and diversity of five different permafrost-affected soils of Northeast Greenland. FEMS Microbiol. Ecol., 2014, 89, 426-441.

12. Marion, G. M. et al., Open-top designs for manipulating field temperature in high-latitude ecosystems. Glob. Chang. Biol., 1997, 3, 20-32.

13. Bokhorst, S. et al., Variable temperature effects of open top chambers at polar and alpine sites explained by irradiance and snow depth. Glob. Chang. Biol., 2012, 19, 64-74.

14. Walker, J. K. M., Egger, K. N. and Henry, G. H. R., Long-term experimental warming alters nitrogen-cycling communities but site factors remain the primary drivers of community structure in high Arctic tundra soils. ISME J., 2008, 2, 982-995.

15. Geml, J., Morgado, L. N., Semenova, T. A., Welker, J. M., Walker, M. D. and Smets, E., Long-term warming alters richness and composition of taxonomic and functional groups of arctic fungi. FEMS Microbiol. Ecol., 2015, 91, 1-13.

ACKNOWLEDGEMENTS. We thank Elise Biersma and Nick Cox (British Antarctic Survey) for assistance in sample collection, and Lee Li Sin (University of Malaya) for guidance in sequence data analysis. We acknowledge the Governor of Svalbard for permitting the sampling of soils (RIS-ID: 6921). Samples were imported to Malaysia under permit JPK141107021232015. K.K.N. and P.C. are supported by NERC core funding to the BAS 'Biodiversity, Evolution and Adaptation' Team, and P.C. by a Visiting Icon Professorship to the University of Malaya. Funding for this study was provided by UMRG (RP002E13SUS \& RP007-2012D) and the MOSTI Flagship Grant (FP0712E012).

doi: $10.18520 / \mathrm{cs} / \mathrm{v} 115 / \mathrm{i} 9 / 1697-1700$ 